\title{
REDES SOCIAIS, EMANCIPAÇÃO POLÍTICA, DESOBEDIÊNCIA CIVIL E MOBILIZAÇÃO - RESGATANDO O PENSAMENTO DE KANT E THOREAU
}

\author{
GUSTAVO CHAVES LOPES \\ Universidade de Brasília \\ Brasília, Distrito Federal, Brasil \\ e-mail: jornal.gustavo@gmail.com
}


REDES SOCIAIS, EMANCIPAÇÃO POLÍTICA, DESOBEDIÊNCIA CIVIL E MOBILIZAÇÃO - RESGATANDO O PENSAMENTO DE KANT E THOREAU

Resumo: as Redes Sociais se converteram em uma interessante ferramenta de mobilização política da sociedade. Mais do que isso, permitiram ao cidadão confrontar de maneira mais contundente as instituições do Estado. Para além da euforia com as novas tecnologias, o presente artigo pretende resgatar autores que estavam na gênese destas ideias - muito antes da Internet aparecer - e a ressonância de seus pensamentos nos movimentos contemporâneos de protesto, que se utilizaram das Redes Sociais para organizar manifestações em escala global. Palavras chave: Desobediência civil; emancipação política; redes sociais; ativismo digital; democracia direta.

\title{
REDES SOCIALES, EMANCIPACIÓN POLÍTICA, DESOBEDIENCIA CIVIL Y MOVILIZACIÓN - RESCATANDO EL PENSAMIENTO DE KANT Y DE THOREAU
}

Resumen: Las redes sociales se han convertido en una interesante herramienta para la movilización política de la sociedad. Más que eso, permitió a los ciudadanos confrontar de manera más incisiva las instituiciones del Estado. Más allá de la euforia con la nueva tecnología, este artículo tiene como objetivo rescatar a los autores que se encontraban en la génesis de estas ideas - mucho antes de que aparezca la Internet - y la resonancia de sus ideas sobre los movimientos de protesta actuales, que utilizan las redes sociales para organizar manifestaciones en escala de global. Palabras clave: Desobediencia civil; emancipación política; redes sociales; activismo digital; democracia directa.

SOCIAL NETWORKS, POLITICAL EMANCIPATION, CIVIL DISOBEDIENCE AND MOBILIZATION - RESCUING THE THOUGHT OF KANT AND THOREAU

\begin{abstract}
The Social Medias have become an interesting tool for political mobilization of society. More than that allowed citizens to confront more incisively state institutions. Beyond the euphoria with the new technology, this article aims to rescue authors who were in the genesis of these ideas - long before the Internet appear - and the resonance of his thoughts on contemporary protest movements, which used the social networks to organize demonstrations in scale global.
\end{abstract}

Keywords: civil disobedience; political emancipation; social media; digital activism; direct democracy. 


\section{INTRODUÇÃO}

As redes sociais sempre existiram. O ser humano é um animal gregário que sempre estabeleceu laços pessoais, vínculos relacionais e, portanto, redes sociais. Assim, reconhecendo esse caráter anterior do conceito de redes, vamos nos referir aqui às redes sociais no âmbito das novas tecnologias da informação, notadamente a Internet. $\mathrm{E}$, dentro delas, tentar identificar elementos que se relacionem com conceitos estabelecidos muito antes de seu surgimento.

A metodologia que embasa esse artigo é, portanto, uma revisão bibliográfica de autores que se debruçaram sobre essa temática, bem como da democracia direta, da participação popular, do ativismo e dos movimentos emancipatórios.

As recentes manifestações que vêm acontecendo ao redor do mundo são, de certa forma, tributárias dos movimentos iniciados nos países do norte da África e que ficaram conhecidos como Primavera Árabe. Os eventos começaram na Tunísia, em dezembro de 2010, quando milhares de pessoas foram às ruas exigir mudanças políticas depois que o vendedor ambulante Mohamed Bouazizi se autoimolou, na cidade de Sidi Bouzidi, em protesto contra a corrupção das autoridades locais.

O exemplo da Tunísia encorajou outros países da região a seguir o mesmo caminho. Em poucos dias o Mundo Árabe ${ }^{1}$ foi sacudido por ondas revolucionárias que repercutiram em todo o planeta. Logo, Egito, Líbia, lêmen, Jordânia, viram suas populações nas ruas exigindo reformas políticas. Em pouco tempo os governos foram depostos nestes países. Omã, Jordânia, Marrocos, Argélia, Arábia Saudita, entre outros países da região, sentiram a força das revoltas populares, ainda que com menor intensidade.

Em comum nessas manifestações, resguardadas as demandas características de cada país, o fato dos manifestantes terem se utilizado das redes sociais para se mobilizar e driblar a censura imposta pelos governantes nos meios de comunicação locais e ao trabalho da imprensa internacional.

As demandas dos países do Magreb, no entanto, são bem diversas daquelas

\footnotetext{
10 conceito de Mundo Árabe remonta ao início do movimento arabista no final do séc. XIX e início do séc. XX. Abrange geograficamente a região do Magreb, que indica o "poente" (da Líbia à Mauritânia); do Macherq, o "levante" (que vai do Egito ao Iraque); e o Khalíf (Estados do Golfo e da Península Arábica). (FARAH, 2011). O termo é comumente atribuído a Michel Aflaq, fundador do partido Baath. (FERABOLLI, 2009).
} 
REDES SOCIAIS, EMANCIPAÇÃO POLÍTICA, DESOBEDIÊNCIA CIVIL E MOBILIZAÇÃO

buscadas nos países que a Primavera inspirou. Ainda assim, as queixas na Europa, nos Estados Unidos, em outras partes do mundo e, mais recentemente, no Brasil, guardam semelhanças entre si: insatisfação com o sistema político; falta de perspectivas sociais; altos índices de desemprego (ainda que no Brasil essa última característica não se observe). Mas, um dos pontos mais convergentes (e que interessa em especial a este artigo) é o fato de todas elas terem sido planejadas, organizadas, deflagradas e potencializadas através das redes sociais.

Muitos desses eventos ganharam uma escala global a partir, sobretudo, do ano de 2011. Movimentos como o Indignados² ou 15M³, surgidos na Espanha; o Occupy Wall Street ${ }^{4}$ ou 99\%5, nos EUA; entre outros, tiveram inúmeras versões, alvos e demandas, dependendo do local onde aconteciam.

Touraine (2006) questiona se pode-se usar o termo "movimentos sociais" para esse tipo de mobilização. Para ele, os movimentos sociais propriamente ditos são aqueles que objetivam uma transformação profunda na sociedade e teriam ficado no passado, como a luta de classes, por exemplo. Embora deixe a questão em aberto, Touraine sugere que não se descarte o uso clássico do termo movimentos sociais para as mobilizações que têm lugar na atualidade, no que ele chama de sociedade pós-industrial (TOURAINE, 2006, p.27).

\section{ORIGENS DO DISCURSO DEMOCRÁTICO}

Este artigo pretende, no entanto, resgatar a origem desses discursos emancipatórios e suas possíveis ressonâncias nos atuais movimentos. Para tanto, traremos para a discussão textos seminais no âmbito da emancipação política, da desobediência civil e de conceitos de democracia direta.

Assim, é possível identificar nessas manifestações, sobretudo em seus dis-

2 Movimento iniciado na Espanha, em maio de 2011, que protesta contra o sistema político, o desemprego e a corrupção no governo.

3 Movimento iniciado em 15 de maio de 2011, em Madri. É a origem da mobilização dos Indignados.

4 Mobilização que teve início em Nova York, em setembro de 2011, protestava contra as desigualdades econômicas e a crescente influência do mercado financeiro no governo dos EUA. Inspirou mobilizações semelhantes em centenas de cidades no mundo.

5 Slogan e segmento do movimento Occupy Wall Street. 
cursos, ecos do que autores como o alemão Immanuel Kant ou o americano Henry David Thoreau diziam alguns séculos atrás. O objetivo central deste artigo é, portanto, demonstrar como estes autores influenciaram, ainda que indiretamente, uma práxis discursiva no âmbito das redes sociais.

A primeira vista pode parecer um tanto ousado colocar na mesma frase (ou ideia) esses autores e as modernas tecnologias digitais. Ainda mais quando se reconhece que a obediência às leis e a negação, a priori, do direito de resistência, aparecem como imperativos categóricos no idealismo kantiano. Mesmo assim, parece-nos que uma leitura mais atenta permite encontrar algumas observações positivas do autor em relação a este tema.

Assim, a ideia de "saída da menoridade" que Kant propunha, inaugurou um conceito de emancipação do indivíduo que permanece extremamente atual. Aliás, pode-se ver claramente nos eventos da Primavera Árabe uma tentativa, por parta das populações daqueles países, de se chegar à maioridade. E no caso de nações que viviam sob regimes ditatoriais, como o Egito e a Tunísia, para citar apenas dois exemplos, essa renúncia à tutela do Estado é ainda mais significativa.

O que esses movimentos buscam é justamente uma maior autonomia política, uma democracia mais participativa, onde o cidadão tenha mais espaço no processo político. Significa dizer: a cidadania pode ser exercida de forma mais direta, e não apenas através da representação política do eleito, pelo qual, afinal, esse cidadão não se sente representado. Esses movimentos tentam, portanto, resgatar um ideal de democracia direta, que Bobbio afirma nunca ter sumido por completo:

O ideal da democracia direta como a única verdadeira democracia jamais desapareceu, tendo sido mantida em vida por grupos políticos radicais, que sempre tenderam a considerar a democracia participativa não como uma inevitável adaptação do princípio da soberania popular às necessidades dos grandes Estados, mas como um condenável ou errôneo desvio da ideia originária do governo do povo, pelo povo e através do povo. (BOBBIO, 2007, p.154).

Mesmo essa questão da representação já aparecia de forma clara em Kant, quando ele propõe que "o que, porém, não é lícito a um povo decidir com relação a si mesmo, menos ainda um monarca (Estado) poderia decidir sobre ele, pois sua autoridade legislativa repousa justamente no fato de reunir a vontade de todo o povo na sua" (Kant, 1985, p.110). 
REDES SOCIAIS, EMANCIPAÇÃO POLÍTICA, DESOBEDIÊNCIA CIVIL E MOBILIZAÇÃO

Assim, tem-se aí, talvez, o germe de um discurso revolucionário que iria inspirar diversos movimentos e pensadores que, por "meio de suas obras escritas podem fazer seus reparos a possíveis defeitos das instituições vigentes" (Kant, 1985, p.110). Kant adverte, no entanto, que não bastariam as revoluções para a transformação social: esta só viria através do conhecimento, já que "uma revolução poderá talvez realizar a queda do despotismo pessoal ou da opressão ávida de lucros ou domínios, porém nunca produzirá a verdadeira reforma no modo de pensar" (KANT, 1985, p.104).

\section{Mobilizações sociais e democracia}

Exemplo claro disso pode-se ver no Egito. As manifestações ajudaram a derrubar um regime despótico e ditatorial e, no entanto, muitas demandas continuam a espera de uma resolução. Agora mesmo, passados quase três anos da renúncia de Hosni Mubarak, os egípcios continuam na Praça Tahrir. A pressão popular contribuiu para que as Forças Armadas do país dessem mais um golpe militar, ainda de contornos imprevisíveis. Ao que parece, a sociedade egípcia está dividida e a ocupação das ruas ainda vai perdurar.

A instabilidade das conquistas egípcias não impediu, porém, que a mobilização política feita através das redes sociais se espraiasse a outras partes do mundo. E isso se deu, em grande medida, graças ao que Milton Santos (2005, p.23) chamou de "cognoscibilidade do planeta". Ou seja, a capacidade que as novas tecnologias deram de se conhecer o planeta "extensiva e profundamente", em uma simultaneidade até então inédita. Superando o medo da repressão, coube aos jovens árabes dar ao mundo as boas novas. Logo, os eventos que estavam ocorrendo no Magreb rapidamente foram conhecidos, apreendidos e replicados em diversas partes do mundo, sobretudo na Europa.

Cuando el proceso de acción comunicativa induce la acción colectiva y se efectúa el cambio, la emoción positiva más fuerte prevalece: el estusiasmo, que potencia la movilización social deliberada. Los individuos entusiastas y conectados, una vez superado el miedo, se transforman en un actor colectivo consciente. La tecnología y morfología de estas redes de comunicación dan forma al proceso de movilización y, por tanto, de cambio social, en tanto que proceso y resultado. (CASTELLS, 2012, p.210) 
Assim, esses movimentos ao redor do mundo carregam em seu DNA insatisfações semelhantes as que fizeram os jovens árabes sair às ruas. Ainda que os europeus ou americanos não estivessem lutando por democracia e sim por meIhores condições econômicas, os seus gritos de guerra não eram tão diferentes dos ouvidos no Magreb. E ambos tinham (têm) - além da ideia de emancipação, proposta por Kant - a essência da desobediência civil em seus discursos, já que enxergavam os respectivos governos como culpados por suas mazelas.

Além disso, o filósofo alemão também enxergava uma certa rebeldia, própria do ser humano, que estabelecia um limite para a imposição da vontade do Estado.

Kant vislumbra um alcance limítrofe para as pretensões dos governantes em relação aos seus governados. Por mais que se mantenha um Estado regido por leis, estas leis nunca atuarão completamente na conduta do indivíduo, pois o ser humano se mostra certo modo ingovernável pela sua própria natureza. (SAUERESSIG, 2008, p.39).

Em Kant, o direito de resistência (um dos pilares da desobediência civil), se estabelece quando o governante não age de acordo com o que foi tacitamente contratado com o governado. Rousseau já previa essa possibilidade no seu Contrato Social, mas Kant, parece-nos, vai um pouco além do aspecto formal da questão.

Assim, se pode concluir que a teoria kantiana traduzida por seus imperativos permite o direito de resistência, mesmo que implicitamente como uma condição humana, moral, de internalização. E o direito de resistência é uma questão de consciência, operando no campo das ideias transformadoras de uma sociedade livre. (SAUERESSIG, 2008, p.41).

\section{Desobediência civil}

Enquanto Kant (1985, p.106) dizia que um indivíduo "não age contrariamente ao dever de um cidadão se, como homem instruído, expõe publicamente suas ideias contra as inconveniências e injustiças dessas imposições", por sua vez, Thoreau (1997, p.32) receitava: "sai mais barato, em todos os sentidos, sofrer a penalidade pela desobediência do que obedecer - obedecer faria com que eu me sentisse diminuído".

De formas distintas, ambos propõem uma emancipação do cidadão em relação ao Estado. Nas palavras de Thoreau, em seu manifesto "Desobediência 
REDES SOCIAIS, EMANCIPAÇÃO POLÍTICA, DESOBEDIÊNCIA CIVIL E MOBILIZAÇÃO

Civil”, podemos ver mais claramente essa relação: “O próprio governo, que é simplesmente uma forma que o povo escolheu para executar a sua vontade, está igualmente sujeito a abusos e perversões antes mesmo que o povo possa agir através dele" (Thoreau, 1997, p.35).

Thoreau vai mais além, sugerindo que um governo pode, por vezes, não representar a vontade do povo que o elegeu, tornando-se uma inconveniência, já que para ele "o governo, no melhor dos casos, nada mais é do que um artifício conveniente; mas a maioria dos governos é por vezes uma inconveniência, e todo governo algum dia acaba por ser inconveniente" (Thoreau, 1997, p. 37). Ele diz ainda que se a legislação que o governo estabelece para os governados "for de natureza tal que exija que nos tornemos agentes de injustiça para com os outros, então proponho que violemos a lei" (1997, p.26).

Neste ponto, é inegável a tentação de interpretar as propostas do autor como anarquistas e vincular a esse conceito as manifestações surgidas no âmbito das redes sociais. De fato, diversos autores anarquistas são reconhecidamente tributários das ideias de Thoreau. Além deles, Bobbio chega a perguntar: "E se o Estado fosse um mal e além do mais não fosse necessário?" (Bobbio, 2007, p.31). Porém, reconhece que isso levaria a uma sociedade anárquica.

Thoreau, porém, não pretendia o "fim do governo e sim um governo meIhor". Para isso ela não abria mão da revolução, já que via nela uma forma de protesto legitimada pelo "direito de negar lealdade e de oferecer resistência ao governo sempre que se tornem grandes e insuportáveis a sua tirania e ineficiência". O autor se referia, no entanto, a uma revolução pacífica e espontânea, que tinha a desobediência ao governo como elemento principal.

Desobedecer é o verbo que se define como central na teoria de Thoreau. A desobediência é fundada na tentativa de fazer com que a instituição visada por determinado movimento, geralmente os governos ou os atos vinculados a estes governos, percebam que existem cidadãos que estão insatisfeitos com o contrato firmado. Sendo assim, se trata de um fenômeno imprevisível, pois sua eclosão não depende de uma previsão legislativa concreta e sim de violação ao que de mais concreto representa a lei para o indivíduo. (SAUERESSIG, 2008, p.87)

Antes de chegar aos manifestantes das redes sociais esse "modelo revolucionário" de resistência, baseado na desobediência civil, encontrou seguido- 
res em figuras emblemáticas do século XX, como Martin Luther King, Nelson Mandela e Mahatma Gandhi.

King, nos Estados Unidos, e Mandela, na África do Sul, lançaram mão da desobediência civil e da mobilização cidadã para combater a segregação racial em seus países. Gandhi utilizou o texto de Thoreau como receituário em sua campanha de independência da Índia. Sua Marcha do Sal, em 1930, simbolizou o início da resistência ao domínio britânico e suas ações continuadas de desobediência civil, seguidas por milhões de indianos, trariam a independência em 1948.

Esse mesmo conceito viria a inspirar, algumas décadas depois, o francês Stéphane Hessel. Um dos grandes ícones do movimento dos "Indignados", Hessel foi membro da resistência francesa na $2^{\circ}$ Guerra Mundial e continuou na ativa até fevereiro de 2013, quando morreu aos 95 anos. Confessamente inspirado em Thoreau, ele publicou no final de 2010 o manifesto "Indignai-vos" (Indignez-vous!), um texto chave para o movimento. Ali ele convoca a juventude a indignar-se contra o sistema e as injustiças do mundo, através de:

uma verdadeira insurreição pacífica contra os meios de comunicação de massa, que, como horizonte para nossos jovens, só sabem propor o consumo de massa, o desprezo aos mais fracos e à cultura, a amnésia generalizada e a competição desenfreada de todos contra todos. (HESSEL, 2010, p.36).

O movimento dos "Indignados" e outros tantos pelo mundo, buscaram responder a esse chamado. Milhares de jovens conectaram-se ao redor do planeta e foram às ruas, pacificamente, em busca de sua emancipação política. Não reconheciam em seus governos representantes de suas demandas. Com seus gritos de guerra, cartazes e máscaras de Guido Fawkes ${ }^{6}$, eles acampavam em praças, ruas e parques. Era um sinal claro de desobediência civil, já que em

6 Guido Fawkes (originalmente Guy) foi um soldado inglês que em 1605 participou de uma conspiração para assassinar o rei Jaime I. O plano era explodir o parlamento inglês durante uma sessão em que o monarca estaria presente. O golpe foi descoberto e Guido foi torturado e executado. Mas ele passou para história como um homem que "enfrentou o sistema". Até hoje, em todo o dia 05 de novembro, imagens de Guido são "malhadas" pelas ruas de Londres. Sua história foi adaptada no filme "V de Vendeta" e a máscara que o personagem usava ficou muito popular também nos movimentos dos "Indignados", embora seja o "emblema oficial” do grupo de hackerativistas "Anonymus". 
REDES SOCIAIS, EMANCIPAÇÃO POLÍTICA, DESOBEDIÊNCIA CIVIL E MOBILIZAÇÃO

todos os lugares as autoridades proibiram a "tomada de espaços públicos".

Mesmo assim, e até por isso mesmo, esses jovens tinham fé de que estavam fazendo a coisa a certa. Assim como Thoreau, eles acreditavam que:

Ações baseadas em princípios - a percepção e a execução do que é certo - modificam coisas e relações; a ação deste gênero é essencialmente revolucionária e não se reduz integralmente a qualquer coisa preexistente. Ela cinde não apenas Estados e Igrejas; divide famílias; e também divide o indivíduo, separando nele o diabólico do divino. (Thoreau, 1997, p.22).

\section{Redes de indignação e democracia direta}

Além disso, a participação efetiva e engajada de milhares de jovens estabelecia um interessante paradoxo: a mesma juventude que era tida como supérflua ou alienada, que só pensava em divertir-se - e divertir-se significa estar de acordo, no dizer de Adorno e Horkheimer (1985) - pois essa mesma juventude surpreendeu o mundo com uma gigantesca onda contestatória. Conectados e atuantes, nas redes e nas ruas, esses jovens estabeleceram novas formas de resistência. Aliás, essa hibridização entre espaço real e virtual, Castells (2012) chama de espaço da autonomia.

El motivo es que la autonomia sólo se puede garantizar mediante la capacidad de organización en el espacio de libertad de las redes de comunicación, pero al mismo tiempo únicamente se puede ejercer como fuerza transformadora si se desafía el orden institucional disciplinario recuperando el espacio de la ciudad para sus ciudadanos. La autonomia sin desafío se convierte en retirada. El deafío sin una base permanente de autonomía en el espacio de los flujos equivale a un activismo discontinuo. El espacio de autonomía es la nueva forma espacial de los movimimientos sociales en red. (CASTELLS, 2012, p.13).

Em seus atos de resistência Mandela, Luther King e Gandhi não puderam contar com as potencialidades das novas tecnologias e das redes sociais. Até porque, como nos lembra Milton Santos, "a cada evolução técnica, uma nova etapa histórica se torna possível” (Santos, 2005, p.24).

Ainda, o uso de modernas tecnologias pelos cidadãos comuns (não especialistas) foi possível através do que Walter Benjamin (1985) chamou de "apro- 
priação da técnica". Ou seja, a banalização da técnica permitiu que a "massa" tivesse acesso aos meios de comunicação e passasse, ela mesma, a comunicar. Uma leitura possível é que ela possibilitaria um empoderamento da sociedade através desses atributos técnicos que estavam então disponibilizados. O que não significa dizer que essa apropriação seja sempre positiva, mas permite uma certa emancipação.

No entanto, essa possibilidade de resistência e participação política através da tecnologia e dos meios de comunicação já havia sido proposta por Brecht, como nos fala Muniz Sodré:

Bem antes de McLuham, já a partir da segunda década deste século, o dramaturgo e poeta alemão Bertold Brecht apresentava, com seu panfleto intitulado "teoria do rádio", a utopia tecnológica de uma sociedade conversacional, dialógica, em que, por meio da radiodifusão, todos poderiam confluir para um consenso, e as massas poderiam exigir diretamente prestações de contas ao Estado (SODRÉ, 2002, p. 72).

Aqui nos parece que há uma aproximação mais precisa do que este artigo propõe: a tecnologia, nomeadamente as relacionadas à comunicação, potencializando um ideal de emancipação cidadã e participação política da sociedade, surgidos muito tempo atrás. Não se pretende supor que as redes sociais sejam o Santo Graal da sociedade contemporânea - longe disso. Parece-nos, porém, que elas tornam mais eficazes uma mobilização que é gerada, essencialmente, no âmbito da realidade social. Não são elas que criam a revolução, mas elas se constituem em mais uma ferramenta (ou arma, se preferirmos) de empoderamento da sociedade.

Sobre isso, Castells fala que "este es el nuevo contexto, en el corazón de la sociedad red como nueva estructura social, en la que se están formandos los movimientos sociales del siglo XXI" (CASTELLS, 2012, p. 210).

Em Comunicação nos movimentos populares Cicilia Peruzzo dizia - ainda nos primórdios da Internet - que "na prática, os meios de comunicação popular, apesar de sua importância e de seu significado político, não chegam a colocarse como forças superadoras dos meios massivos" (PERUZZO, 1998, p. 130). Parece-nos que, enfim, os meios de comunicação popular (aqui entendidos como as redes sociais, sobretudo) superaram os meios massivos, possivelmente engendrando uma inversão da teoria do agendamento. 
REDES SOCIAIS, EMANCIPAÇÃO POLÍTICA, DESOBEDIÊNCIA CIVIL E MOBILIZAÇÃO

É possível reconhecê-las, portanto, como uma mídia alternativa, proporcionando um espaço de publicização à margem da imprensa alinhada (muitas vezes) ao status quo. Muniz Sodré alerta que "em certos espaços nacionais, a autocensura jornalística, imposta pelos proprietários em função de seus interesses empresariais, pode ser tão ou mais severa que o controle do Estado" (SODRÉ, 2002, p.74).

Pode-se, ainda, ir mais além, vendo nas redes sociais o que Downing chama de "mídias radicais". Aliás, neste autor (e neste conceito), encontramos ainda ecos das propostas de Thoreau e Kant:

Os movimentos sociais constituem uma das expressões mais dinâmicas de resistência, em comparação com instituições mais estáveis e duradouras, como sindicatos ou partidos. (...) A ascensão desses movimentos parece ocasionar e, ao mesmo tempo, ser ocasionada pela mídia radical. (DOWNING, 2002, p.55).

Ainda que vejamos com ceticismo o caráter revolucionário possibilitado com as tecnologias da comunicação, essas revoluções, deflagradas através dessas novas mídias, têm um valor em si mesmas. Foucault, por exemplo, comentando Kant, nos fala da importância da revolução como acontecimento. Ou seja, "pouco importa que ela tenha êxito ou fracasse, isso não é o sinal do progresso que buscamos" (Foucault, 2010, p.18). Ela é também uma maneira de sair da "menoridade", de governar-se por si. "É sinal, primeiro, de que todos os homens consideram que é do direito de todos se dotar da constituição política que Ihes convém e que eles querem" (Foucault, 2010, p. 19).

Em Kant encontramos também uma característica tão comum a esses movimentos revolucionários: "O significativo é a maneira como a revolução faz espetáculo, é a maneira como é recebida em toda a sua volta por espectadores que não participam dela, mas a veem, que assistem a ela e que, bem ou mal, se deixam arrastar por ela" (KANT in FOUCALT, 2010, p. 19). Ou seja, o caráter global das manifestações contemporâneas não deixa ninguém de fora. Todos, de uma forma ou de outra, são atingidos por ela.

Como dito anteriormente, há que se ter o cuidado de não estabelecer as novas tecnologias como o arauto absoluto da participação política na atualidade. Até porque nem toda a sociedade possui amplo acesso a essas ferramentas e não pode, por conta disso, ser alijada do processo democrático. Esse neces- 
sário cuidado fica claro no dizer de Milton Santos, nos alertando que "quando um determinado ator não tem as condições para mobilizar as técnicas consideradas mais avançadas, torna-se, por isso mesmo, um ator de menor importância no período atual" (Santos, 2005, p. 25).

Kant falava que permanecer na menoridade era culpa do próprio homem. Emancipar-se, ousar saber (sapere aude) dependia apenas dele. Mas era mais fácil para muitos homens permanecer na menoridade, ficando assim a mercê de tutores que os governassem. As redes sociais, é bom que se repita, não são a saída para a maioridade, que propunha Kant. Apenas o conhecimento pode levar ao esclarecimento. Mas elas podem ser um caminho de emancipação social, através do qual o cidadão vivencie mais diretamente a democracia, lembrando (talvez utopicamente) as origens desse conceito.

Relatando os primórdios dessa ideia em seu livro Origens do discurso democrático, Donaldo Schüller afirma que "não há democracia na vigência do discurso único. Porém, não se espere que a democracia resolva os conflitos, ela os cultiva. É no espaço público que os argumentos respiram, é lá que são eficazes" (Schüller, 2001, p. 27).

Os movimentos surgidos no âmbito das redes sociais procuram retomar o espaço público. Fez-se da ocupação das praças, ruas e avenidas - e da experiência de democracia direta que ali se desenhava - uma reinvindicação em si mesma.

Buscam, através desses meios, executar o que Brecht havia proposto: "uma sociedade dialógica, conversacional”, onde a o cidadão enfrentaria o Estado de forma organizada e consensual. Essa "utopia tecnológica", como fala Sodré, talvez esteja se desenhando, para além dos contornos pré-definidos pelo status quo.

Nas décadas anteriores o meio de comunicação dominante e hegemônico era a televisão. E essa mídia, por natureza, sempre privilegiou a passividade e a inércia. Por outro lado, a internet, sobretudo a partir das inovações do 2.0, estimula a interatividade, a ação e a reação. Ou seja, enquanto a televisão isola, a internet conecta.

Assim, ainda que não sejam as redes sociais as principais responsáveis por essa onda revolucionária global, ela ofereceu ferramentas valiosas para a sua difusão. 
REDES SOCIAIS, EMANCIPAÇÃO POLÍTICA, DESOBEDIÊNCIA CIVIL E MOBILIZAÇÃO

\section{O manifestante dos novos tempos}

O fato é que o mundo não via mobilizações em escala global desde os anos sessenta. Elas vieram para ficar e transformar o que se entendia por protestos, revoluções, contestações e movimentos do gênero. As características dos manifestantes é que mudaram, embora a essência ainda seja a luta por uma sociedade mais justa. A revista Courrier Internacional relata que em um congresso na Alemanha para debater o tema foi identificado um perfil comum nesse novo manifestante:

Demarca-se totalmente das figuras do militante e do guerrilheiro dos séculos passados. Não tem a obsessão ideológica do séc. XX, nem se deixa seduzir pela luta armada. [...] Acima de tudo, tem a paciência - quase espiritualidade - que nos habituamos a associar à desobediência civil, longe da euforia e da catarse, tantas vezes fatais, da luta armada. (COURRIER INTERNACIONAL, 2011. p.39).

Há um consenso, entre os participantes desses eventos de que, ainda que as redes sociais não sejam imprescindíveis para as mobilizações, com elas as possibilidades de sucesso são muito maiores. Foi através delas, por exemplo, que os egípcios estipularam o dia 25 de janeiro (2011) como a data em que iriam às ruas para manifestar sua indignação contra o governo. Foi por meio das redes sociais que se organizaram os Indignados na Espanha e em diversos outros países. Enfim, a internet e suas ferramentas tiveram um papel central para canalizar uma insatisfação latente e uma energia difusa que havia nas ruas. Por meio delas esse desejo de emancipação política pode se organizar em desobediência civil e buscar novas formas de participação cidadã e democrática. A sociedade agora tem novas formas de se mobilizar e estreitar os laços que formam as suas redes.

Reconhecemos que existem, contemporaneamente, diversos autores que falam dessas novas formas de protesto de maneira mais atualizada. Manuel Castells, por exemplo, fala em wikirrevoluções (CASTELLS, 2011). Há ainda os termos ativismo digital, ciberativismo, revoluções digitais, revoluções em rede, etc. - todos querendo dizer, basicamente, a mesma coisa, ou seja: uma cidadania potencializada por meio das novas tecnologias, uma participação política engendrada nas redes sociais ou, ainda, um computador conectado estabelecendo o empoderamento da sociedade. 
É forçoso admitir, também, que existem autores contemporâneos que veem de forma não tão positiva a organização e mobilização política da sociedade, bem como a democracia direta. Ortega y Gasset (1962), por exemplo, critica o que chamava de "ação direta das massas". Ele via a presença das massas como um retrocesso cultural e civilizatório. Enquanto a sociedade se organizava em campos intermediários havia o equilíbrio e o bom senso. Porém, quando as massas começam a intervir diretamente inicia-se um processo de desgaste do tecido social. A massa, para Ortega y Gasset, abandona a civilização. Para ele, depois da humanidade haver atingido um grau satisfatório de civilização com a democracia representativa, a ação direta seria um retrocesso civilizatório.

Outro autor que não via com bons olhos a questão da participação direta da sociedade na práxis política era Gabriel Tarde. O pensador francês acreditava que as massas não tinham opinião. Ele afirmava que na multidão havia alguns poucos líderes com opinião que guiavam os demais. Uma das características das mobilizações atuais, no entanto, é justamente a ausência de lideranças definidas.

\section{CONCLUSÕES}

Ainda que haja, felizmente, vozes dissonantes no debate sobre a participação direta e mobilização política da sociedade, parece-nos apropriado resgatar textos seminais como os de Kant e Thoreau, que estão na origem desses discursos democráticos e emancipatórios. Mesmo que reconheçamos que no tempo de Kant e antes de Thoreau, portanto, esses conceitos já haviam sido propostos, por exemplo, em Hobbes com sua resistência anárquica e Rousseau com sua motivação através da quebra de contrato.

Parece-nos, no entanto, que a ideia de uma cidadania plena, na acepção mais ampla do termo, apareceu de forma mais clara nestes textos ancestrais de Kant e Thoreau. Ali se encontram os fundamentos - tão perenes quanto atuais - da luta pela participação política, da vontade de ser ouvido, da democracia, da liberdade, em última instância. Assim era na visão dos gregos antigos: "A democracia não é outorgada. Direitos democráticos são duramente conquistados. Homens que não lutam pela liberdade não estão maduros para viver livremente" (SCHÜLLER, 2001, p.16).

Assim é na visão de milhares de indignados mundo afora: "Acredita- 
REDES SOCIAIS, EMANCIPAÇÃO POLÍTICA, DESOBEDIÊNCIA CIVIL E MOBILIZAÇÃO

mos que podemos mudá-lo (o mundo). Acreditamos que podemos ajudar. Sabemos que, unidos, podemos. Venha conosco! É o teu direito". (Manifesto dos Indignados, 2011).

As articulações políticas sempre fizeram parte da história da humanidade. A luta pelos seus direitos é algo mais recente. Combinar esses conceitos com as novas tecnologias de comunicação, em especial as redes sociais, parece ser uma tendência irreversível. Seja através da desobediência civil - que nos leve a uma emancipação política - seja através das manifestações globais (com demandas locais) a democracia está definitivamente inserida nessa ambiência digital. Assim, torna-se importante não perder de vista os fundamentos teóricos e conceituais dessa vontade de tornar o mundo um lugar mais justo e o homem um ser mais autônomo e consciente. Porque, mesmo que antigos, eles ainda ressoam em nossas cabeças.

\section{REFERÊNCIAS}

ADORNO, T., HORKHEIMER, M. Dialética do Esclarecimento. Rio de Janeiro: Jorge Zahar, 2008.

BENJAMIN, W. Magia e técnica, arte e política. Brasília: Brasiliense, 1985.

BOBBIO, N. Estado, governo e sociedade. São Paulo: Paz e Terra, 2007.

CASTELLS, M. La wikirrevolución de jazmín. La Vanguardia. Disponível em: http://www. lavanguardia.com/opinion/articulos/20110129/54107291983/la- wikirrevolucion-del-jazmin. html>. Acesso em 12/07/2012.

Redes de Indignación e Esperanza. Madrid: Alianza, 2012.

COURRIER INTERNACIONAL (2011). Protesto Global: quem são os novos combaten-

tes? Courrier Internacional, Lisboa n¹89, p.39. Novembro, 2011.

DOWNING, J. D. Mídia Radical: rebeldia nas comunicações e movimentos sociais. São Paulo: SENAC, 2002.

FARAH, P. D. A Primavera Árabe no Macherq, Maghreb e Khalíj: motivações e perspectivas. Revista Política Exterior, São Paulo, volume 20, n 1, p. 45-55, jun./jul./ago. 2011.

FERABOLLI, S. Relações Internacionais do Mundo Árabe. Curitiba: Juruá, 2009. FOUCAULT, M. O Governo de si e dos outros. São Paulo: Martins Fontes, 2010.

HESSEL, S. Indignai-vos! São Paulo: Leya, 2011.

INDIGNADOS Manifesto dos Indignados. Disponível em: http://www.democraciarealya.es/ manifiesto-comun/ - Acesso em 30/07/2012. 
KANT, I. Textos Seletos., Petrópolis, RJ: Vozes, 1985.

ORTEGA Y GASSET, J. A Rebelião das Massas. Rio de Janeiro: Livro Ibero-americano, 1962.

PERUZZO, C. K. Comunicação nos Movimentos Populares. Petrópolis, RJ: Vozes, 1998.

SANTOS, M. Por uma outra globalização, São Paulo: Vozes, 2005.

SAUERESSIG, J.O Direito fundamental de resistência e a Constituição de

1988. Santo

Ângelo, RS: URI, 2008.

SODRÉ, M. Antropológica do espelho. Petrópolis, RJ: Vozes, 2002.

SCÜLLER, D. Origens do discurso democrático. Porto Alegre: L\&PM, 2001.

TARDE, G. A Opinião e as Massas. São Paulo: Martins Fontes, 2005.

THOREAU, H. A Desobediência Civil. Porto Alegre: L\&PM, 1997.

TOURAINE, A. Na Fronteira dos Movimentos Sociais., Revista Sociedade e Estado, Brasília, v. 21, n. 1, p.17-28, jan/abr, 2006.

RECEBIDO EM: 01/11/2013

ACEITO PARA PUBLICAÇÃO: 20/11/2013

\section{Gustavo Chaves Lopes}

Mestrando do PPGCOM - FAC/UNB (2012-2013). Pesquisador do Laboratório de experimentação em linguagens digitais para dispositivos móveis e desenvolvimento de novos produtos jornalísticos para tablets e smartphones (LALIM). Professor da oficina de Jornalismo Digital (FAC UnB). 
